\title{
Téoros
}

Revue de recherche en tourisme

\section{Tourisme et cultures régionales devant la crise de l'identité québécoise}

\author{
Un compte rendu des interventions de M.-A. Tremblay
}

\section{Marc Laplante}

Volume 7, numéro 1, mars 1988

Cultures régionales et tourisme

URI : https://id.erudit.org/iderudit/1080422ar

DOI : https://doi.org/10.7202/1080422ar

Aller au sommaire du numéro

Éditeur(s)

Université du Québec à Montréal

ISSN

0712-8657 (imprimé)

1923-2705 (numérique)

Découvrir la revue

Citer cet article

Laplante, M. (1988). Tourisme et cultures régionales devant la crise de l'identité québécoise : un compte rendu des interventions de M.-A. Tremblay. Téoros,

7(1), 3-4. https://doi.org/10.7202/1080422ar d'utilisation que vous pouvez consulter en ligne.

https://apropos.erudit.org/fr/usagers/politique-dutilisation/ 
Un compte rendu des interventions de M.--A. Tremblay

Marc Laplante*
Tourisme et cultures

régionales devant la crise

de I'identité québécoise
Le colloque Téoros de mai 1987 s'est ouvert par une allocution de M. Marc-Adélard Tremblay, anthropologue de l'Université Laval qui publiait en 1983 un livre intitulé: Lidentite québécoise en péril (Éd. St-Yves). Sa communication s"appuyait sur un texte récent qui constituait une mise a jour de son livre ${ }^{(1)}$; elle a donne lieu à plusieurs échanges entre le conférencier et les participants. Je voudrais rendre compte de l'essentiel des interventions de M.A. Tremblay tout en m'attardant surtout sur celles qui m'ont semblé particulièrement pertinentes au thème général du colloque.

Il convient d'abord de préciser la notion même d'identité culturelle; ensuite, il faudra faire état de la crise actuelle de cette identité et des facteurs qui peuvent l'expliquer; finalement, nous discuterons des régions culturelles. Ce demier point sera l'occasion de chercher des espoirs pour l'avenir et laissera aux gens du tourisme des themes forts riches pour approfondir les rapports entre les cultures régionales et le développement touristique.

\section{Note explicative}

I1) Une première version de ce texte est parue dans Lan morphologie sociale en mutation au Quefhec, Ies Cahiers de l'ACFAS, mo 41, 1986, sous le titre; "Mor.

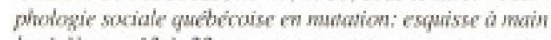

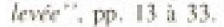

"M. Laplante, sociologue, est professeur au Dépertement d'études urbaines et touriatiques de l'Université du Québec à Montrial.
La notion d'identité culturelle

L'identité culturelle renvoie à l'ensemble des traits et elements qui singularisent une culture donnee et a la valeur symbolique d'attachement que ces éléments représentent chez. ceux qui la constituent. Par cette façon de découper le réel, nous rejoignons les trois aspects distinctifs qui fondent l'identité culturelle. Elle est, d'abord, une inage de soi, en tant que collectivité, constitucée par les representations collectives se rapportant à l'ensemble des caractéristiques d'une ethnie. Elle est encore, un genre de vie qui se déploie dans les rapports interpersonnels que les individus appartenant à une ethnie particuliere entretiennent entre eux sur un territoire donné et dans les relations économiques, politiques et sociales avec l'extérieur. L'identité ethnoculturelle, est, enfin, whe vision du monde, qui s"appuie tout autant sur une interprétation du vécu collectif que sur l'explication de projets se rapportant à la communauté ethnique. Chacune des pieces de ce tryptique est essentielle pour comprendre les systèmes d'identification, les cadres significatifs de référence et les projets collectifs de développement.

\section{L'identité québécoise}

Les québécois francophones ont construit leur identité au cours de la seconde moitié du XIXe siècle. Cette identité les a défini jusque vers les annes ' 50 bien qu'elle connut quelques signes avant-coureurs de crise après la dépression des années '30 et au cours de la seconde guerre mondiale.

Les éléments autour desquels s'est greffece la conscience nationale ont été 1) l'ascendance française, 2) l'appartenance à l'église catholique et 3) le parler québécois de cette période. A ces éléments se sont ajoutées des institutions qui pouvaient les consolider: Ie mariage à l'intérieur du groupe ethnique, la création d'écoles confessionnelles, la création de structures religieuses comme la paroisse, etc. La civilisation canadiennefrançaise vers 1880 -1900 était essentiellement une civilisation de type ruraliste à vocation agricole. Les éléments prédominants de son système de valeurs sont une vision spiritualiste du monde (interprétation de tous les événements par des forces spirituelles, par la Providence) et un système d'autorité qui énoncait des normes de conduite pour assurer la survie. Celle-ci était le premier objectif du groupe francophone.

Dès cette époque, ce nationalisme dit de conservation était ambitieux: il visait la survi- vance des francophones au Québec mais aussi au Canada et en Amérique du Nord (ces francophones avaient immigres partout à la fin de ce siècle). Ce nationalisme portait donc en lui une sorte d'espérance et la civilisation française qui avait fleuri au Québec avait une mission spirituelle à la dimension de l'Amerique du Nord.

Il faudra une conjoncture de plusieurs facteurs pour ébranler cette identité culturelle et la structure sociale qui $l^{*}$ incarnait. Pourtant, des évolutions rapides et de moins en moins finalisées vont accumuler des tensions, des ambiguittés, des contractions et même des paradoxes dans les images que les québécois ont d'eux-mêmes, dans leurs genres de vie et dans leurs visions d'avenir.

\section{L'identité québécoise en crise}

Les multiples facteurs qui, à partir des années '30 vont installer l'état de crise, ont exerce une pression constante sur les formes êlémentaires de la vie sociale des québécois, sur ce qu'on appelle sa morphologie sociale. M.A. Tremblay concentre son analyse sur quatre structures: la technologic, la démographie, $I^{\dagger}$ économie et l'État. Dans chaque cas, il rappelle d'abord les déstructurations qui ont suivi l'abandon des formes traditionnelles sur lesquelles la culture francophone quebécoise avait installé ses systèmes explicatifs, les normes et les règles de conduites de ses membres; il montre ensuite que les restrueturations observables sont le plus souvent instables, fragiles et surtout, sans "guides", sans principes directeurs largement admis par les intéressés. La morphologie sociale du Québec a muté en moins de vingt ans: il ne $s^{\prime a g i t ~ p l u s ~ d ' e ́ v o l u t i o n ~ r a p i d e ~ m a i s ~ d e ~ s a u t s ~}$ brusques, sans continuité souvent entre l'avant et l'après, conme de véritables métamorphoses parfois.

Que la culture de façon gentrale ne suive pas, qu'elle soit un lieu d'affrontement plutơt que de consensus, l'ethnologue qui s'occupe de modernitế ne s'en étonnera pas. Mais M.A. Tremblay en tant qu'analyste de la culture francophone québeccoise a su percevoir aussi que les chocs des mutations morphologiques seraient particulièrement violents sur une culture traditionnelle francophone qui avait trouvé sa force au cours du siecle précédent dans son opposition à la société industrielle montante; celle-ci avait pour champions ses voisins immédiats et omniprésents: le Canada-anglais et les États-Unis.

Le Québec "a êté industrialise", comme territoire de matières premières d'abord et 
comme suocursale de l'industric du temps de guerre ensuite. Quand il entreprendra son "rattrapage" (1965-1975), il essaiera de ressembler aux sociétés industrialisées par rapport auxquelles il se definit comme en "retard" ${ }^{+}$. Le désir de ressembler aux autres, plus "évoluếs", la volonté de s"affirmer comme "moderne", progressisté, avantgarde même (ex.: Expo '67), at tenu licu de principe directeur, de "règles du jeu". Dans ce contexte idéologique, on comprend mieux que les grandes institutions québécoises aient pu expédier leurs anciennes valeurs dans l'oubli (comme on a sorti des maisons les vieux meubles) et epouser - sans examen de santé préalable - les nouvelles idées. Le rattrapage, au fond, ne consiste qu'à courir pour rejoindre le peloton de tête: il n"implique pas qu'on se questionne pour savoir où va ce peloton et quels sont les sentiments qui l'animent.

Alors, les québécois ayant de plus en plus de mal à répondre à la question: qui sommesnous? ne peuvent pas répondre à l'autre question: où allons-nous? Collectivement, les québécois d'avant les années ' 50 pouvaient dire pourquoi ils etaient ici, en cette terte d'Amérique, et ce qu'ils avaient à faire dans ce bas monde. Les mutations survenues dans la morphologie sociale ont multiplić les visions d'avenir, ellargi l'éventail des options, enrichi les espérances, introduit plusieurs nouveaux discours; l'ancienne cohésion sociale est disparue; 1'individualisme de la société de masse a fait le reste: il y a presque autant de "projets de société" qu'il y a de quebécois et les francophones n'arrivent plus à exprimer en quoi leur projet de sociétét est original. Même la langue française, avec laquelle ils ont conduit leur plus recente bataille d'affirmation (loi 101) subit constamment des amputations là même ou elle servait de symbole de distinction: dans l'affichage public.

La crise d'identité ethnique des Québécois francophones est donc à l'origine comme au terme d'une situation individuelle et collective qui reflète le désarroi, c'est-à-dire une incapacité d'effectuer des choix raisonnés. Elle est encote l'amorce comme la résultante d'un décalage significatif entre une situation objective (les failts de réalité) et une situation anticipée ou espérée. La crise s'exacerbe lorsque plusieurs facteurs se conjuguent pour créer chez l'individu un sentiment soit d'incertitude et de détachement, ou encore d'impuissance et de frustration. Dans ce dernier cas surtout, l'individu se perçoit comme étant à la merci de pressions et de tensions sur lesquelles il n'exerce aucun contrôle. En bref, la crise renvoie à des événements, à des situations et des expériences nouvelles qui suscitent des déséquilibres et provoquent des temps d'arrêt dans le processus d'acquisition de compétences nouvelles qui, se prolongeant, risque de créer une régression.

\section{Les cultures régionales}

Le second theme de la communication de M.-A. Tremblay traitait de la culture régionale. Celle-ci est définie comme un ensem- ble d'éléments culturels qui, en interactions les uns avec les autres, produisent une configuration culturelle particulière laquelle, par ses traits distinctifs at le vécu de ses résidents, est susceptible de se differencier des autres existantes.

A l'origine d'une culture régionale, on doit trouver whe strategie d'adaptation ecologique. Un groupe, s'installant sur un territoire, doit aussitôt faire des choix quant au mode de peuplement, à l'utilisation des ressources, aux formes techniques, economiques et sociales pouvant satisfaire les besoins au groupe. Au Québee, à l'origine, les villages furent centrés sur la péche, l'agriculture, la forét; une sorte de combinaison agroforestière a marqué l'histoire de nombreuses communautés du Québec jusqu'à l'industrialisation. L'adaptation des populations au milieu physique - et l'histoire de cette adaptation - sont des êléments indispensables à If compréhension des traits culturels spécifiques d'une région.

Lhistoire, celle qui accompagne l'occupation de l'espace, est le facteur principal de différenciation d'une région par rapport à une autre. Par exemple, deux territoires riches en ressources agro-forestieres peuvent avoir des traits culturels différents aujourd'hui parce qu'ils ont une histoire propre. Ainsi. il faut se rappeler l"histoire de la colonisation française au Québec pour saisir comment se sont constitues les villages de la vallée du St-Laurent; de meme, on comprendra fort peu les cultures des tégions pertiphériques du Québec (hors de la vallé du Si-Laurent) sans revenir à l'histoire des groupes québécois qui sont partis pour coloniser ces lointains espaces.

Avec les dimensions spatio-temporelles, il convient aussitôt de référer à l'univers symbolique pour saisir les types de reprotsentations et de discours sur la réalité que se sont donnes, at travers le temps, les groupes fixés sur les territoires. On observera alors les parlers particuliers, les vocabulaires typiques, les accents toniques spéciaux, les styles de communication. Le nouveau-venu aura du mal à saisir le sens et la portée de certains messages et gestes; il en sera ainsi pour comprendre aussi les préoccupations du groupe, les expériences qu'il valorise, les manières de les raconter. Pourtant, le champ de l'identité s'élabore à ce niveau qui révềle des conceptions de soi intégrant des visions de l'avenir. Enfin, le langage, par sa fonction vitale, est plus que le miroir de la réalité, il est fabricant de culture.

Les éléments de l'univers symbolique qu'un groupe se donne, dans un territoire donné. finissent par s'exprimer dans une vision consensuelle du monde. C'est une conception subjective de la réalité selon les modes de pensée et les catégories locales de ceux qui la vivent; c'est un tout dont on peut essayer de saisir les grandes composantes: image de soi, conception du milieu ambiant et des relations que les habitants entretiennent avec ce milieu, une conception de l'univers, une image de la vie, de lạ mort et de l'au-delà, un sens du merveilleux et de l'extraordinaire. Par exemple, pour l'ensemble du Québec à la fin du XIXe siècle, on trouvait une vision consensuelle forte: les québécois étaient un peuple choisi, fort et courageux, prédestiné à de grandes réalisations en terre d'Amérique. Ce nationalisme de conservation a fait vivre la société québécoise en tant que telle durant presque un siecle.

Une conscience régionale doit alors venir "couronner" l'édifice culturel car, après l'adaptation au territoire, la satisfaction des besoins du groupe, la constitution d'un univers symbolique propre, un partage des projets $\mathrm{d}^{+}$avenir, on peut s'attendre ă ce que le groupe saisisse avec plus de conscience son existence comme entité sociale. Cette conscience est d'abord et avant tout constituée d'un sentiment d'appartenance, de l'existence d'un "nous" collectif, bien circonscrit et distinctif. L'appartenance s'exprimera par les solidarités dans les revers comme dans les réussites, par des obligations de support mutuel, par la capacité de faire cause commune contre les menaces extérieures, etc.

\section{Tourisme et cultures régionales}

Si tels peuvent étre les principaux paramètres pour l'observateur d'une culture inscrite sur un territoire et formant une tégion culturelle, celui-ci devrait pouvoir reconstituer une sorte de biographie particuliere de chaque région pour en dégager la "personnalité de base". Il lui faudra, à oct observateur, une grande familiarité avec lc milieu et les gens qu'il étudie.

Sans entreprendre une discussion de fonds sur la tâche qui consisterait aे "traduire" ces biographies particulières au profit des visiteurs etrangers qui souhaiteraient venir en ces régions culturelles pour en apprécier l'originalité, il apparaît assez clairement qu'une telle tâche devrait d'abord être confiée à des chercheurs en sciences humaines ayant aussi des affinités culturelles avec la région a exprimer, avee des outils de recherche appropriés et avec les populations concernées, il n'est pas impossible de faire se raconter une culture régionale. On imagine bien cependant les risques d'une telle opération et l'impossibilité de produire une biographie régionale figee et valable en toutes circonstances.

Et ceci est d'autant plus vrai qu'au Québec actuellement, devant la crise d'identitế culturelle qui a suivi la période du nationalisme de rattrapage, le "nous" québécois devra probablement passer par les régions pour arriver à se reformuler peut-etre un jour. Apres les grands chambardements des 40-50 dernieres années, il faut aller voir dans les diverses "petites sociétés" "des régions pour trouwer certains éléments qui pourraient bien, un jour, donner un nouveau portrait du Québec. Mais ce processus est en cours et se poursuit de façon différente selon les territoires. Dans cette conjoncture, les attentes de ceux et celles qui s'occupent du tourisme pourraient encourager ces processus à condition que ces intervenants s'y intègrent sans chercher à les court-circuiter ou à les simplifier à l'extrềne. $f$ 